\title{
Potential Environmental Benefits from Regulatory Consideration of Synthetic Drilling Muds
}

Environmental Assessment Division Argonne National Laboratory

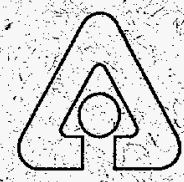

Operated by The University of Chicago, under Contract W-31-109-Eng-38, for the

United States Department of Energy 


\section{Argonne National Laboratory}

Argonne National Laboratory, with facilities in the states of Illinois and Idaho, is owned by the United States Government, and operated by the University of Chicago under the provisions of a contract with the Department of Energy.

This technical memo is a product of Argonne's Environmental Assessment Division (EAD). For information on the division's scientific and engineering activities, contact:

Director, Environmental Assessment Division

Argonne National Laboratory

Argonne, Illinois 604394815

Telephone (708) 252-3107

Presented in this technical memo are preliminary results of ongoing work or work that is more limited in scope and depth than that described in formal reports issued by the $E A D$.

\section{Publishing Support Senvices}

Publishing support services provided by Argonne's Information and Publishing Division.

\section{Disclaimer}

This report was prepared as an account of work sponsored by an agency of the United States Government. Neither the United States Government nor any agency thereof, nor any of their employees, makes any warranty, express or implied, or assumes any legal liability or responsibility for the accuracy, completeness, or usefulness of any information, apparatus, product, or process disclosed, or represents that its use would not infringe privately owned rights, Reference herein to any specific commercial product, process, or service by trade name, trademark, manufacturer, or othenwise, does not necessarily constitute or imply its endorsement, recommendation, or favoring by the United States Government or any agency thereof. The views and opinions of authors expressed herein do not necessarily state or reflect those of the United States Government or any agency thereof.

Available to DOE and DOE contractors from the Office of Scientific and Technical Information, P.O, Box 62, Oak Ridge, TN 37831 , prices available from (615) $576-8401$.

Avallable to the public from the National Technical Information Service, U.S. Department of Commerce, 5285 Port Royal Road, Springtield, VA 22161. 


\section{Potential Environmental Benefits from Regulatory Consideration of Synthetic Drilling Muds}

by C.J. Burke and J.A. Veil

Environmental Assessment Division,

Argonne National Laboratory, 9700 South Cass Avenue, Argonne, Illinois 60439

February 1995

Work sponsored by United States Department of Energy, Office of Policy 
बry

This report is printed on recycled paper. 


\section{DISCLAIMER}

Portions of this document may be illegible in electronic image products. Images are produced from the best available original document. 


\section{CONTENTS}

NOTATION $\ldots \ldots \ldots \ldots \ldots \ldots \ldots \ldots \ldots \ldots \ldots \ldots \ldots \ldots \ldots \ldots \ldots \ldots \ldots$

ACKNOWLEDGMENTS $\ldots \ldots \ldots \ldots \ldots \ldots \ldots \ldots \ldots \ldots \ldots \ldots \ldots$ vi

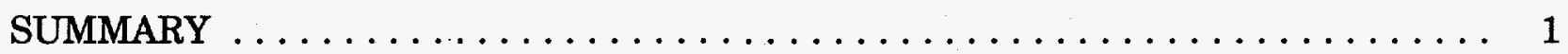

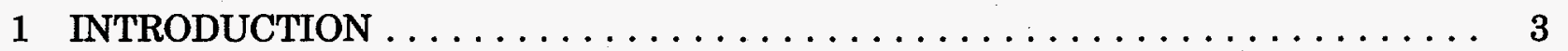

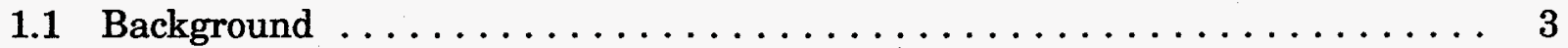

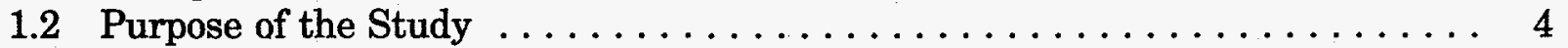

1.3 Description and Purpose of Drilling Muds $\ldots \ldots \ldots \ldots \ldots \ldots \ldots \ldots$

1.4 Water-Based Versus Oil-Based Drilling Muds $\ldots \ldots \ldots \ldots \ldots \ldots \ldots \ldots$

1.5 Regulatory Background $\ldots \ldots \ldots \ldots \ldots \ldots \ldots \ldots \ldots \ldots \ldots \ldots \ldots \ldots \ldots$

2 TECHNOLOGY DESCRIPTION AND OVERVIEW $\ldots \ldots \ldots \ldots \ldots \ldots \ldots$

2.1 Characterization of Technology for Synthetic-Based Muds . . . . . . . . 8

2.2 Uses and Advantages of Synthetic-Based Muds . . . . . . . . . . . 9

2.3 Limitations of Traditional Drilling Techniques ................ 10

3 COMPARATIVE COST/BENEFIT CASE STUDIES $\ldots \ldots \ldots \ldots \ldots \ldots \ldots$

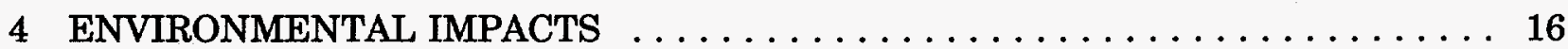

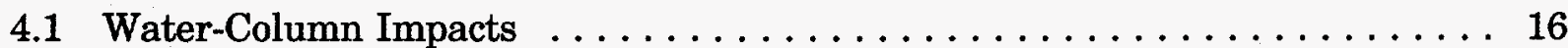

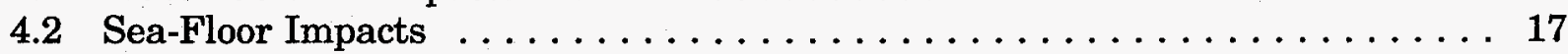

4.3 Non-Water-Quality Environmental Impacts . . . . . . . . . . . . 20

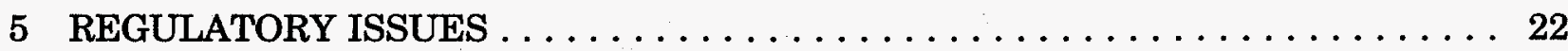

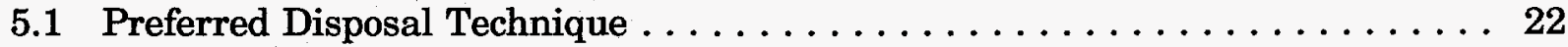

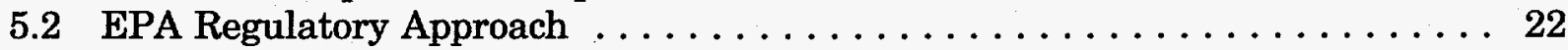

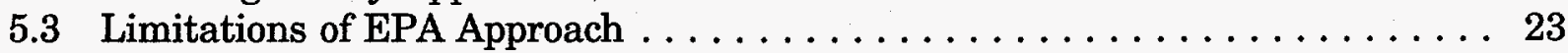

6 CONCLUSIONS AND RECOMMENDATIONS $\ldots \ldots \ldots \ldots \ldots \ldots \ldots \ldots \ldots$

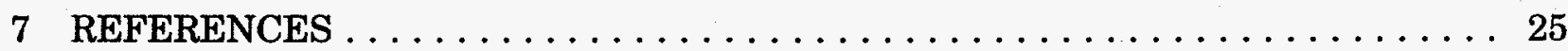

\section{TABLES}

1 Performance Comparison of WBM versus SBM $\ldots \ldots \ldots \ldots \ldots \ldots \ldots$

2 Comparison of Two Sea-Floor Studies at a Well Drilled with an Ester-Type SBM $\ldots \ldots \ldots \ldots \ldots \ldots \ldots \ldots \ldots \ldots \ldots \ldots$

3 Benthic Conditions after Two Years at a Well Partially Drilled with a PAO-Type SBM 


\section{FIGURE}

1 Causes of Delays in Drilling Time with the Use of WBMs at Five Offshore Wells Representing 871 Drilling Days 


\section{NOTATION}

The following is the list of acronyms and abbreviations used in this report.

$\begin{array}{ll}\text { BAT } & \text { best available technology } \\ \text { BPJ } & \text { best professional judgment } \\ \text { BPT } & \text { best practicable technology } \\ \text { CWA } & \text { Clean Water Act } \\ \text { ELGs } & \text { effluent limitations guidelines } \\ \text { FR } & \text { Federal Register } \\ \text { EPA } & \text { U.S. Environmental Protection Agency } \\ \text { LC50 } & \text { lethal concentration to 50\% of test organisms } \\ \text { NPDES } & \text { National Pollutant Discharge Elimination System } \\ \text { OBM } & \text { oil-based mud } \\ \text { OOC } & \text { Offshore Operators Committee } \\ \text { PAOs } & \text { polyalphaolefins } \\ \text { ppm } & \text { parts per million } \\ \text { SBM } & \text { synthetic-based mud } \\ \text { TPH } & \text { total petroleum hydrocarbons } \\ \text { WBM } & \text { water-based mud }\end{array}$




\section{ACKNOWLEDGMENTS}

The authors appreciate the support and encouragement of David Moses, U.S. Department of Energy, Office of Policy. We are also grateful for the assistance of an industry work group in reviewing the draft report and providing helpful comments. We particularly thank Dan Caudle, Robert C. Ayers, Jr., and John Candler for assistance in collecting information and providing guidance. 


\title{
POTENTIAL ENVIRONMENTAL BENEFITS FROM REGULATORY CONSIDERATION OF SYNTHETIC DRILLING MUDS
}

\author{
by
}

\author{
C.J. Burke and J.A. Veil
}

\section{SUMMARY}

When drilling exploration and production wells for oil and gas, drillers use specialized drilling fluids, referred to as "muds," to help maintain well control and to remove drill cuttings from the hole. Historically, either water-based muds (WBMs) or oil-based muds (OBMs) have been used for offshore wells. Recently, in response to U.S. Environmental Protection Agency (EPA) regulations and drilling-waste discharge requirements imposed by North Sea nations, the drilling industry has developed several types of synthetic-based muds (SBMs) that combine the desirable operating qualities of OBMs with the lower toxicity and environmental impact qualities of WBMs. This report describes the operational, environmental, and economic features of all three types of muds and discusses potential EPA regulatory barriers to wider use of SBMs.

The EPA's effluent limitations guidelines (ELGs) prohibit releases of free oil, as detected by the static sheen test, from drilling fluids and drill cuttings discharges. In addition, limits are placed on the cadmium and mercury content and the toxicity of discharges. Most WBMs can meet these requirements, and consequently spent WBMs and drill cuttings are typically discharged at the well site (on-site). WBMs are widely used in the Gulf of Mexico in shallow wells and often in shallower portions of deeper wells. However, in deep or extended-reach wells, the performance of WBMs is often poor. The drilling pipe can become stuck in the hole, causing delays in drilling and loss of time and money. Thus, for deeper well intervals and complex drilling situations, OBMs and SBMs are frequently used for their superior performance.

Both OBMs and SBMs are recycled, with only the cuttings and a small amount of associated drilling fluids being disposed of. Because of the ELGs restriction on free oil, OBMs cannot be discharged on-site. OBMs may also pose greater risk than WBMs and SBMs to workers through skin irritation and the effects of inhalation. The added transport and disposal costs, as well as potential liability issues, associated with OBMs have restricted widespread OBM use.

SBMs have superior drilling performance and lower environmental impact than OBMs. In one example, wells drilled in the Gulf of Mexico with WBMs averaged 116 feet per day and had an average total cost of $\$ 12$ million per well. Similar wells drilled in the same area with SBMs averaged 336 feet per day and had an average cost of $\$ 5.8$ million per well. The cost savings from using SBMs rather than WBMs can be extremely large in some cases. 
Even for many shallower or less complicated wells, the cost savings are smaller but still significant. Many operators, both in the United States and abroad, currently use and would like to continue using SBMs as their mud of choice in complicated or deep-drilling situations. Some oil and gas producers have performed internal cost estimates and concluded that for their operations, SBMs are more cost-effective. For most such cost analyses, the factor that tips the balance toward using SBMs is the ability to discharge the cuttings on-site and thus avoid the costs, logistic difficulties, and potential liabilities of transporting the cuttings to shore for disposal.

Discharged drilling muds and cuttings do not remain in the water column long enough to directly affect swimming or floating organisms. Discharges of WBMs and cuttings do not generally cause any long-term or widespread impacts to the sea floor. Discharge of OBM cuttings, on the other hand, have been found to inhibit benthic abundance and diversity for at least several years to a distance of 500 meters from the discharge point. Preliminary data on the sea-floor effects of SBM cuttings suggest that these muds cause much lower impacts than OBMs and that SBM impacts are limited temporally and spatially.

SBMs offer operational advantages and great pollution prevention potential in many situations, but the widespread use of SBMs has been inhibited by concerns that the discharged drill cuttings would not meet the ELGs requirement for no free oil. The static sheen test is intended to detect free crude oil, diesel oil, or mineral oil in drilling mud discharges. The continuous phase of some SBMs is lighter than water and could cause a detectable film in the static sheen test apparatus. While this film is not caused by the type of free oil that the EPA intended as an indicator of priority pollutants, its presence might be interpreted as a failure of the sheen test and thus preclude on-site discharge of the associated drill cuttings. The static sheen test procedure or interpretation of results should be clarified or amended to ensure that the original intent is accomplished without inadvertently subjecting a wide range of pollution-preventing SBMs to unnecessary barriers. 


\section{INTRODUCTION}

\subsection{BACKGROUND}

Efficient drilling technology is essential to meet the needs of the oil and gas industry. Both the challenges of new oil provinces, especially in offshore waters, and the demands for effective environmental protection have prompted the development of new technology. A key factor influencing drilling technology is the drilling fluid used. New oil industry developments facilitated by improved drilling fluids include horizontal and extended-reach drilling, as well as drilling in frontier areas and to increased depths. Such capabilities and conditions demand careful attention to the selection and engineering of efficient drilling fluid systems.

Drilling fluids and drill cuttings form one of several waste streams from oil and gas exploration and development activities. The term drilling fluid generally applies to fluids used to help maintain well control and remove drill cuttings (particles from underground geological formations) from holes drilled in the earth. Drilling fluids are an essential technology for oil and gas development. They can pose a costly disposal problem for offshore operators who must haul spent fluids and cuttings to shore for land disposal if those materials do not meet U.S. Environmental Protection Agency (EPA) discharge limitations and permit requirements.

The EPA regulations place drilling fluids into classes based on the continuous phase forming the main components. The major types of drilling fluids are water, oil, synthetic fluid, and, in rare cases, gas. When the drilling fluid's main component is water, oil, or synthetic base fluid, the fluid is called mud, which is the most widely used drilling fluid. Gas-based fluids are used only rarely in special situations. This report refers to drilling fluids as muds, since it addresses only oil-based, water-based, and synthetic-based muds (OBMs, WBMs, and SBMs).

The drilling industry often encounters operating conditions in which a WBM will not perform adequately. Historically, the industry substituted OBMs to overcome these difficulties. The EPA's effluent limitations guidelines (ELGs) for the offshore discharge of drilling wastes affected the economic feasibility of industry operations by precluding the on-site discharge of drill cuttings associated with OBMs. Companies supplying mud systems and other related chemicals have responded to this problem by finding substitutes for WBMs and OBMs. Since 1990, several low-toxicity, biodegradable SBMs with impressive performance and environmental characteristics have entered the market. However, EPA's ELGs are based on the technology that was widely available when the regulations were developed. While EPA regulations, along with restrictions on discharge of cuttings from OBMs in the North Sea, appear to have been major reasons for development of SBMs, concern is now focused on the inhibiting effect of discharge limitations on application of alternative mud technologies. 


\subsection{PURPOSE OF THE STUDY}

This report examines and describes SBM systems recently developed as substitutes for conventional drilling mud systems in certain circumstances. SBMs have the potential to drill wells more quickly and efficiently than WBMs, while avoiding some of the disposal costs and environmental difficulties associated with OBMs. Wider use of SBMs in offshore areas could result in avoidance of direct and indirect environmental impacts while also reducing operating costs. However, EPA regulations may pose a barrier to wider use of SBMs.

The following sections first present background information on drilling muds. The report then identifies the advantages and disadvantages of alternative drilling muds and assesses their comparative environmental impacts and cost/benefit. The report also characterizes the regulatory factors that affect the introduction and widespread use of an innovative alternative mud technology. Finally, the report assesses the approach of EPA in implementing ELGs by issuing discharge permits under the National Pollutant Discharge Elimination System (NPDES) and the impact of that approach on innovative technology development. The report also recommends areas of further study and suggests regulatory process improvements to encourage the development and use of an alternative mud technology.

\subsection{DESCRIPTION AND PURPOSE OF DRILLING MUDS}

Drilling muds are an essential part of the drilling operation. The composition of drilling muds ranges from simple WBMs to complex non-aqueous-based muds. Geology, geography, and economics are major considerations in selecting the mud type used for any particular well. Additional factors considered include drilling performance, anticipated well conditions, worker safety, fluid cost, and waste disposal costs. While WBMs are usually the mud of choice, some situations require use of other systems to provide acceptable drilling performance. Drilling fluids serve several important purposes:

- Carrying cuttings to the surface for disposal,

- Cooling and cleaning the drill bit,

- Maintaining pressure balance between geological formations and the borehole,

- Lubricating the bit and drill string,

- Reducing friction in the borehole,

- Sealing permeable formations, and

- Stabilizing the borehole. 
Drilling muds are formulated to minimize problems associated with geological formations, well chemistry, depth, and other factors. A major challenge facing mud engineers is to stabilize and control mud properties to optimize drilling performance as cost-effectively as possible.

A diverse array of mud additives is available to respond to most problems or significant changes in down-hole conditions. Some mud additives, however, may increase mud toxicity; substantial research has yielded less toxic alternatives. Additives to WBMs include agents to control viscosity, specific gravity, lubricity, temperature, corrosive influxes, and other properties.

\subsection{WATER-BASED VERSUS OIL-BASED DRILLING MUDS}

WBMs are by far the most commonly used muds, both onshore and offshore; EPA (1993a) estimates that nearly all shallow wells (less than 10,000 feet deep) and about 85\% of wells deeper than 10,000 feet are drilled with the use of WBMs. These muds generally consist of more than $90 \%$ water by volume, with added amounts of barite, clays, lignosulfonate, lignite, caustic soda, and other special additives for specific well conditions. For example, bentonite, a volcanic clay, is used to increase mud viscosity and enhance its ability to lift drill cuttings from the hole's bottom to the top, where they can be removed. The EPA (1993a) reports that use of WBMs generates between 7,000 and 13,000 barrels of waste per well, of which 1,400-2,800 barrels consist of drill cuttings, depending upon the depth and diameter of the well. The National Research Council (1983) reports that the volume of drill cuttings with adhering WBMs continuously discharged during drilling totals about 3,0006,000 barrels per well and that intermittent bulk discharges of WBMs represent another $5,000-30,000$ barrels of WBM waste per well.

The performance of WBMs is deficient for some applications, and OBMs have been developed and refined over the last 30 years to overcome these deficiencies. The type of OBM most commonly used in the Gulf of Mexico is an oil and brine emulsion containing various additives dispersed in oil. OBMs have traditionally been used to improve lubricity, minimize problems associated with water-sensitive formations, and deal with other site-specific conditions (such as high temperature) for which WBMs are not suited. OBMs are used where WBMs are dangerous, technically impossible, or uneconomical to use. OBMs are usually rented or sold and repurchased by the supplier. These muds generally consist of a base oil (usually diesel or mineral oil), barite, clays, emulsifiers, water, calcium chloride, lignite, lime, and other additives (McMordie 1980).

Oil-based muds have been the drilling fluid of choice for a range of special situations, including high temperatures, hydratable shales, high-angle, extended-reach wells, highdensity mud, and drilling through salt. Because of their enhanced lubricity, oil-based "spotting fluids" (which may be chemically different from OBMs) are also used as "spotting pills" during drilling operations with WBMs when the drill pipe becomes stuck in the hole. A spotting fluid is a substance added to an existing circulating mud system to free stuck drill pipe. Typically it is applied as a discrete dose known as a spotting pill. In some cases, 
synthetic-based spotting fluids have also been used to free stuck pipe. Stuck drill pipe is a problem for many operators in the Gulf of Mexico. The Offshore Operators Committee (OOC) reports that in 2,287 wells drilled from 1983 to 1986 in the Gulf of Mexico, 506 instances were identified in which the operator used an oil additive in attempts to free stuck pipe (OOC 1987). Although WBM systems have improved since the mid-1980s, drilling programs have become more complex, resulting in many incidents of stuck pipe.

The inability of WBMs to effectively suppress the hydrational tendencies of some water-sensitive formations can result in hole enlargement or collapse. This problem frequently can be controlled only with OBMs or SBMs, which do not hydrate the shale and thus maintain hole stability.

Wells drilled with OBMs normally produce lower waste volumes than those drilled with WBMs because very little slumping or caving in of the walls of the hole occurs, and the mud is reconditioned and reused rather than discharged. In some cases, WBMs augmented with costly synthetic-based additives are also recycled, but most WBMs are discharged along with the drill cuttings. A relatively small volume of WBMs not meeting EPA's discharge limitations is hauled to shore for land disposal; in most cases, these muds are contaminated with oil and did not pass the sheen test (Burke 1994).

In contrast, in wells drilled with OBMs, the muds are recycled and only the drill cuttings are disposed of. The average volume of OBM waste (drill cuttings with OBMs adhering to the cuttings) is estimated at 2,000 to 8,000 barrels per well (Ayers 1994). However, OBM wastes cannot be discharged on-site under the EPA's ELGs because they contain oil. In U.S. offshore areas, most of this waste is hauled to shore for land disposal. Two methods are used for disposal of cuttings generated from wells drilled with OBMs or with WBMs contaminated with oil or other substances making them unsuitable for on-site disposal in a marine environment. The cuttings are either transported to shore for land disposal, or they are injected down the cased borehole into the annulus of the well. Use of these types of disposal for WBMs is infrequent.

Despite their unique and valuable properties, use of OBMs is limited because of the added cost of hauling and disposing of wastes onshore and the long-term liability concerns associated with onshore disposal sites. The development of alternatives such as SBMs may be attractive if those fluids can be shown to be cost-effective and if EPA regulations can be clarified to ensure that SBM cuttings, if environmentally acceptable, can be discharged on-site.

\subsection{REGULATORY BACKGROUND}

Under the Clean Water Act (CWA), EPA regulates discharges of all pollutants, including drilling muds, into U.S. waterways and offshore areas. The EPA uses technologybased effluent standards (generally ELGs) to issue discharge permits to offshore oil and gas industry operators. 
On April 13, 1979, EPA issued final ELGs limiting offshore discharges of drilling mud and other effluents on the basis of the use of best practicable technology (BPT), the first tier of technology-based controls (44 Federal Register [FR] 22069). At that time, the only limitation on drilling mud discharge was a ban on free oil as determined by the visual sheen test. Between 1978 and 1983, EPA allowed discharge only of preapproved, low-toxicity, generic muds and additives in offshore waters (Ayers et al. 1985). EPA's August 26, 1985, proposed offshore ELGs (50 FR 34592) included the first proposed end-of-the-pipe toxicity standard for offshore drilling mud discharges. In the final offshore ELGs issued March 4, 1993 (58 FR 12454), based upon best available technology (BAT), a more advanced level of technology-based controls than BPT, EPA placed several additional limitations on discharge of muds and cuttings:

- No discharges of free oil as detected by the static sheen test,

- A 30,000-ppm 96-hour LC50 toxicity limitation on the suspended particulate phase, ${ }^{1}$

- Limitations on cadmium and mercury content of barite used in muds,

- A ban on discharge of muds and cuttings that contain diesel oil, and

- A ban on discharge of drilling fluids and drill cuttings within three miles of shore.

Through general permits issued by EPA regions, the offshore petroleum industry in the United States has been operating under these or similar restrictions since 1986 for the toxicity limits and since 1992 and 1993 for the other criteria. Before final ELGs were issued in 1993, EPA regional offices included their best professional judgment assessment of the anticipated BAT ELGs in discharge permits.

By discouraging the use of OBMs and requiring the use of less toxic muds, EPA's" regulations, in conjunction with similar developments in the North Sea, created the need for and spurred the development of alternative muds and additives. However, EPA's regulations did not include any specific language that would facilitate the use of innovative SBM technology on a significantly larger scale.

1 A 96-hour LC50 is the concentration lethal to $50 \%$ of test organisms during a 96-hour test. 


\section{TECHNOLOGY DESCRIPTION AND OVERVIEW}

\subsection{CHARACTERIZATION OF TECHNOLOGY FOR SYNTHETIC-BASED MUDS}

In SBMs, the synthetic liquid forms the continuous phase, while a brine serves as the dispersed phase. During drilling operations, the solids in the mud system and the formations are exposed primarily to the synthetic liquid rather than to the aqueous phase, thus preventing swelling and degradation of borehole walls. As is the case for OBMs, most of the drill cuttings are less likely to disperse into the mud when SBMs are used. The system does not need large dilution volumes to control solids, and the volume of spent mud and cuttings is reduced (Park et al. 1993). Several SBM systems currently used can be classified according to the molecular structure of their synthetic base fluids:

- Esters can be synthesized from fatty acids and alcohols. In one manufacturer's product, the fatty acid component of the ester-based material used for SBMs is derived from vegetable oils. The key to the performance characteristics is the proper selection of the hydrocarbon chain length on either side of the ester functional group. These side groups are selected to minimize fluid viscosity, maximize hydrolytic stability, and minimize toxicity.

- Ethers include a range of materials usually synthesized from alcohols. Hydrocarbon groups of ethers are selected to optimize drilling properties and minimize toxicity.

- Polyalphaolefins (PAOs) for drilling are manufactured by the catalytic polymerization of linear alpha-olefins, such as 1-octene or 1-decene. Control over chemical structure and thus physical properties is possible by adjustment of the reaction parameters in the polymerization process and selection of starting alpha-olefins.

- Olefin isomers are manufactured by selective isomerization of normal alpha-olefins. Modifications to the base chemical structure are chosen to minimize kinematic viscosity, yet retain environmental acceptability in acute toxicity and biodegradability tests.

- Other types of base compounds are likely to be developed in the future because use of SBMs is relatively new and continues to evolve.

These various types of SBMs have a wide range of chemical properties and drilling performance. The environmental impacts from different types of SBMs differ as well. Each type of base fluid has advantages and disadvantages for drilling operations and disposal of cuttings. While much of this report refers to SBMs as a general class of materials, it is 
important to recognize that SBMs are not a uniform product. Where possible, the report provides data from more than one type of SBM.

\subsection{USES AND ADVANTAGES OF SYNTHETIC-BASED MUDS}

SBMs have drilling and operational properties similar to OBM systems and are used where OBMs are commonly used in difficult drilling situations (such as high downhole temperatures, hydratable shales or salt) where the properties of WBMs would limit performance. In some instances, SBMs may provide better performance than OBMs. Park et al. (1993) report that laboratory studies found the metal-to-metal coefficient of friction for a PAO-type SBM to be half that of an OBM. Likewise, field experience reported by Park et al. (1993) showed improvements in torque and drag when using PAO-type SBMs versus OBMs. In some cases, SBMs have increased the rate of penetration compared with OBMs (Friedheim 1994a). SBMs have set rate-of-penetration records in the North Sea and the Gulf of Mexico, and both ester-based and ether-based systems were used to set drilling records in the North Sea. However, in spite of these few reported cases, it cannot necessarily be concluded that all SBMs outperform all OBMs.

Although the purchase costs of SBMs generally are several times higher than the costs of OBMs, the cost disadvantage is overcome if cuttings from wells drilled with SBMs can be discharged on-site, saving transportation and disposal costs. SBMs are well-suited to the high-angle, directional, horizontal, and extended-reach wells that are common in the multiwell platform sites in the North Sea, the Gulf of Mexico, and elsewhere. The use of SBMs in the demanding conditions of the North Sea has been facilitated by British, Dutch, and Norwegian regulatory authorities, who have permitted the discharge of SBM cuttings in some instances.

Friedheim (1994a) reports on the number of North Sea wells that have been drilled with SBMs through September 1994 (United Kingdom - 89 wells, Norway - 76 wells, and the Netherlands -4 wells) and characterizes the regulatory climate in each country. The most used type of SBM in the United Kingdom was linear alkyl benzene, which was not used at all in the Netherlands or Norway. Esters were also used extensively. The Norwegian authorities initially welcomed the use of SBMs but more recently have adopted a policy of allowing new types of SBMs in just a small number of wells (3-5) until a full environmental assessment can be made. Most SBMs used in Norway were esters or ether. The Netherlands have only seen limited use of SBMs, primarily PAOs.

The performance of SBMs in drilling wells with large horizontal offsets, in some cases measuring several miles, has prompted significant changes in oil industry operations. The development of horizontal or extended-reach drilling techniques has permitted the use of one platform to drill an increased number of wells, hence reducing the overall number of platforms, operating costs, and associated environmental impacts. Today's technology permits one well to be drilled to check several unassociated pay zones, thus further improving efficiencies. The use of multiwell platforms using OBMs or SBMs is a worldwide trend for the offshore industry (Christiansen 1991). 
SBMs have reduced well completion times compared with WBMs. Similar to OBMs, the SBMs have achieved significant cost savings over WBMs in problem wells because they improve performance (feet drilled per hour) and reduce downtime for common problems such as stuck drill pipe. Use of WBMs is more cost-effective in drilling many shallow wells, and WBMs will continue to be used in those instances. However, for more complicated or deeper wells, SBMs or OBMs are often used because of their ability to drill more quickly. The cost savings can be substantial for some particularly difficult to drill wells. The quantifiable environmental benefits (compared with either WBMs or OBMs, as indicated) that result from use of SBMs include:

- Less waste is produced from a recyclable product (vs. WBMs);

- Elimination of diesel as a mud base lessens the pollution hazard, improves worker safety through lower toxicity and diminished irritant properties, and reduces consequent risk (vs. OBMs);

- Increased use of horizontal drilling reduces the areal extent and the environmental impacts of offshore oil and gas operations (vs. WBMs);

- Shortened drilling time results in reduced air emissions from drilling power sources (vs. WBMs); and

- Improved drilling performance decreases waste-generating incidents such as pipe stuck in the hole. Such incidents necessitate the use of diesel or other oil "pills" that add to the waste load from the mud (vs. WBMs).

SBMs resolve many of the environmental problems associated with most OBMs, while producing comparable drilling performance. For example, if the cuttings are discharged, use of SBMs eliminates the use of expensive onshore disposal facilities. Similar to WBMs, the SBMs exhibit low toxicity, but unlike WBMs, SBMs are recycled, thus reducing the volume of waste discharged. The substantial environmental benefits demonstrated by this new technology appear to justify regulatory consideration. Environmental benefits aside, the leading attribute of SBMs is the efficiency they can bring to drilling. Like OBMs, the SBMs can provide increased lubricity, reduced friction, and improved performance, thus resulting in faster drilling, more rapid completions, and reduced wastes and costs. These factors contribute to the definitive cost savings demonstrated for some SBM projects cited below.

\subsection{LIMITATIONS OF TRADITIONAL DRILLING TECHNIQUES}

Although oil wells were first developed in the nineteenth century and the industry has shown a steady technical growth, development of drilling techniques has been especially rapid in the last 20 years. The technically sophisticated and environmentally sound offshore operation of today is the culmination of technology enhancements, stringent environmental 
requirements, and increased emphasis on resource conservation in an internationally competitive economy.

Despite these major advances in technology and techniques, however, many wells are still subject to problems that have plagued drill operators for a long time. Information provided by Marathon Oil (White 1994a), demonstrates the impact that various types of problems have on drilling time for selected offshore wells drilled with WBMs. As shown in Figure 1, total drilling time loss over 871 operating days at five locations breaks down as follows:

- Mechanical problems - $14 \%$ of the total drilling days, including twist offs, loss of stabilizer blades, and other drill string failures;

- Lost circulation - $10 \%$ of total days, primarily due to insufficient hole cleaning, drilling massive sand sections, and excessive mud weights;

- Hole instability - 7\% of the total drilling days, caused by dispersion of the shale and hole enlargement; and

- Well control, stuck pipe, cementing, and weather - a total of $15 \%$ of the total drilling days.

These data come from relatively deep wells. In Section 3, the effectiveness of drilling these wells with the use of WBMs is compared with the use of SBMs. Unproductive downtime of this order can have a severe impact on project economics. Many of the problems causing this lost productivity may be attributable to the interaction of the drilling mud, the

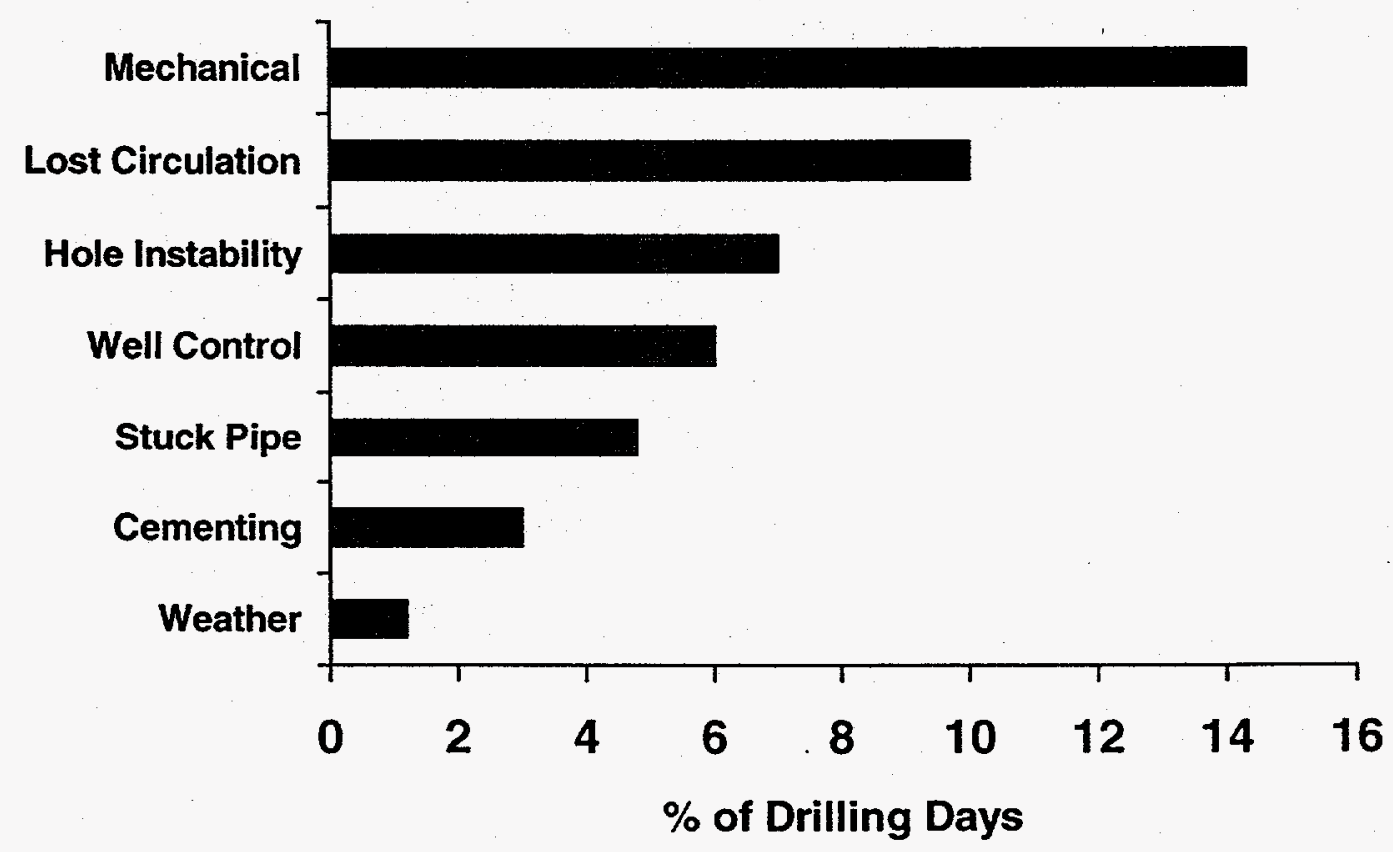

Note: More than one cause of delay may occur on any given day

FIGURE 1 Causes of Delays in Drilling Time with the Use of WBMs at Five Offshore Wells Representing 871 Drilling Days (Source: White 1994a) 
wellbore, and the cuttings, among other things. The scenarios described in the following paragraphs are cited to define the problems confronting operators and to understand the value of new technologies that may resolve these problems.

In a WBM well, as water is absorbed by surrounding clay, clay particles disperse into the drilling fluid, eventually causing a buildup of fine solids in the mud and an unacceptable increase in viscosity. To lower mud viscosity, water is added to dilute the concentration of fine solids. As the mud volume increases from the addition of water, mud additives are applied to maintain the density and flow properties. This increases waste volumes of spent mud and discharges to the environment (Candler et al. 1993).

In an alternative drilling scenario, water reacts with the wellbore, expanding the hydrophilic clays. Sloughing of the clays into the hole increases the size of the annulus, a problem known as hole washout. In the Gulf of Mexico, $30 \%$ hole washout is common, and over $100 \%$ washout has occurred over short sections of a wellbore. As the annulus increases and annular velocities decrease, removal of cuttings from the hole becomes increasingly difficult. Hydration of hydrophilic clays can lead to increased torque and drag on the drill string, bit balling (clogging of clays in the drill bit), and often a stuck drill pipe. When the drill pipe becomes stuck, drilling activities are shut down while a number of measures, including the addition of diesel pills or other spotting fluids, are successively used in attempts to free the stuck pipe. The highest direct cost of stuck pipe is the loss in productivity. From a pollution standpoint, the volume of mud and cuttings discharged will also increase if the hole needs to be redrilled.

Mud additives used in response to the types of drilling problems noted above may increase the toxicity of a WBM. In fact, the application of mud additives is viewed as a balancing act between performance and toxicity. The traditional solution to these problems can include changing to an OBM, which presents a new set of environmental concerns. It is against this backdrop that SBMs have been developed. 


\section{COMPARATIVE COST/BENEFIT CASE STUDIES}

The purchase price of SBMs is higher than that of OBMs and WBMs; however, compared with WBMs, the higher purchase price may be justified by the SBMs' improved performance in problem wells. Compared with OBMs, the higher purchase price of SBMs may be balanced by avoidance of hauling and onshore disposal costs. Comparative field-cost data on different types of muds are scarce. This section presents two sets of preliminary field data that document the substantial economic benefits that may result from the use of SBMs when drilling deep or complex wells.

In the first example, a major oil company provided detailed, verified platform cost and drilling data for a series of wells recently drilled in the Gulf of Mexico under similar conditions and to roughly equal depths (White 1994b). Five of the wells used WBMs and three used PAO-type SBMs. No wells in this example were drilled with OBMs; therefore, it is not possible to compare the drilling effectiveness of OBMs to that of WBMs and SBMs with these data. Selected pertinent data are presented in Table 1 for the eight wells. The data demonstrate major benefits of SBMs over WBMs in several areas:

- As measured by drilled footage per day, SBMs perform with greater overall efficiency than WBMs. WBMs averaged 116 feet drilled per day, while SBMs averaged 336 feet per day.

TABLE 1 Performance Comparison of WBM versus SBM

\begin{tabular}{|c|c|c|c|c|c|c|}
\hline Wells & $\begin{array}{l}\text { Footage } \\
\text { Drilled }\end{array}$ & $\begin{array}{l}\text { Footage } \\
\text { per Day }\end{array}$ & $\begin{array}{c}\text { Total } \\
\text { Mud Cost } \\
\text { (\$ million) }\end{array}$ & $\begin{array}{l}\text { Mud Cost } \\
\text { per Foot }(\$)\end{array}$ & $\begin{array}{l}\text { Total Dry } \\
\text { Hole Cost } \\
(\$ \text { million) }\end{array}$ & $\begin{array}{l}\text { Total Days } \\
\text { (dry hole/ } \\
\text { overall) }\end{array}$ \\
\hline \multicolumn{7}{|c|}{ WBM Wells ${ }^{a}$} \\
\hline C-1 & 17,381 & 215 & $-\mathbf{b}$ & - & 10.1 & $81 / 84$ \\
\hline C-2 & 16,928 & 62 & 2.538 & 149.97 & 14.7 & $274 / 326$ \\
\hline C-3 & 17,540 & 82 & - & - & 9.6 & $214 / 214$ \\
\hline C-8 & 17,981 & 134 & 1.329 & 73.93 & 9.7 & $134 / 163$ \\
\hline $14^{\mathrm{c}}$ & 17,142 & 87 & 1.550 & 90.44 & 12.7 & $197 / 197$ \\
\hline \multicolumn{7}{|c|}{ SBM Wells } \\
\hline $\mathrm{C}-5$ & 16,842 & 301 & 0.806 & 48 & 5.2 & $56 / 60$ \\
\hline C- 6 & 18,122 & 275 & 1.707 & 94 & 6.5 & $66 / 82$ \\
\hline C-7 & 17,250 & 431 & 0.776 & 45 & 4.4 & $40 / 42$ \\
\hline
\end{tabular}

a One additional well not reported here (C-4) was initially drilled with WBMs. After two stuck pipe incidents, the well was redrilled with SBMs and was successfully completed.

b A "-" indicates data not available.

c Well 14 does not follow the other wells in numerical sequence because it was drilled from the same location into an adjacent block with a different numbering scheme.

Source: Data provided by White (1994b). 
- While significantly more costly on a per barrel basis, SBMs can reduce total mud costs and mud cost per drilled foot compared with WBMs. At most of the wells surveyed, the mud cost was lower for SBM wells than for WBM wells.

- The total costs for WBM wells were in the range of $\$ 9.6$ - 14.7 million; the SBM wells cost in the range of $\$ 4.4-6.5$ million. The total dry hole cost for each of the WBM wells was substantially higher than the most expensive SBM wells. SBMs reduce overall costs by reducing downtime and other non-productive activities.

- Improvements in efficiency yield significant increases in productivity. The WBM wells averaged 180 days to complete the dry hole and 197 days overall, while the SBM wells were completed on average in less than one third the time, 54 days to complete the dry hole and 61 days overall.

In this case, the average total dry hole cost of WBM wells was $\$ 11.4$ million, compared with $\$ 5.4$ million for SBM wells. This difference indicates a substantial economic benefit from use of SBMs as an alternative to WBMs. These costs do not include any onshore disposal costs for SBM cuttings. It is not known how conventional OBMs would have performed in these wells.

The second example compares the drilling time and well cost for a Gulf of Mexico well drilled from the surface to 11,610 feet with WBMs and from 11,610 to 18,920 feet with ester-type SBMs to the estimated drilling time and cost, based on prior experience, of a hypothetical well drilled entirely with WBMs (Carlson 1994). The well drilled with WBMs was estimated to cost $\$ 6.6$ million and take about 65 days to complete, while the well drilled with SBMs actually cost $\$ 4.2$ million and took about 32 days to complete.

A third example of drilling performance with the used ester-type SBMs is given by Peresich et al. (1991). Two similar offset wells in the North Sea were drilled over the same depth intervals (total of 9,023 feet) with WBMs used for one well and SBMs for the other. The interval at the WBM well took 701 hours to complete compared with 385 hours for the SBM well. Although no cost figures are provided in Peresich et al. (1991), the savings of 316 hours (over 13 drilling days) surely resulted in greatly lower drilling costs.

In some cases, such as the examples shown above, the cost savings from use of SBMs or OBMs rather than WBMs are extremely large. Even for many shallower or less complicated wells, the cost savings are smaller but still significant. It is clear that the oil and gas industry will use OBMs and SBMs for many drilling applications.

In general, per-barrel costs are several times higher for SBMs than for OBMs. Given that OBMs are less expensive to purchase and provide comparable drilling performance, SBMs must have some economic advantage or they would not be used. It is difficult to find accurate comparative cost data for total drilling and waste disposal costs for OBMs and 
SBMs. Nevertheless, many operators, both in the United States and abroad, are presently using, and would like to continue using, SBMs as their mud of choice in complicated or deep drilling situations. Some oil and gas producers have performed internal cost estimates and concluded that for their operations, SBMs are more cost-effective. For most such cost analyses, the factor that tips the balance toward using SBMs is the ability to discharge the cuttings on-site and avoid the costs, logistic difficulties, and potential liabilities of transporting the cuttings to shore for disposal. 


\section{ENVIRONMENTAL IMPACTS}

\subsection{WATER-COLUMN IMPACTS}

On the basis of modeling results, the EPA (1993b) estimates that discharges of drilling fluids (presumably WBMs) from offshore wells will cause exceedances of EPA's water quality criteria in the water column and in the sediment pore water at a distance of 100 meters from the point of discharge. In the case of water-column effects, two different bioavailability scenarios are considered. Under the more likely scenario (assuming mean seawater leach conditions and BAT-level discharge quality), the only calculated water quality criteria exceedances are for iron (marine chronic) at all modeled depths and arsenic (human health from fish consumption) at the shallowest depth.

Neither of these calculated exceedances represents a meaningful environmental impact. First, iron is not a toxic chemical. It appears that even if iron is considered important in the offshore environment, EPA did not use the appropriate criterion for comparison. The agency has developed no marine chronic criterion for iron, only a freshwater chronic criterion. Second, it is inappropriate to use human health criteria to calculate watercolumn effects because human health criteria are based on a 70-year continuous exposure to the chemical in question, while drilling fluid and drill cuttings discharges typically last from one to three months.

Essentially all the field study results to date suggest that because of rapid settling and dilution, drilling fluid and drill cuttings discharges do not cause significant biological effects in the water column. The National Research Council (1983) reports that about $90 \%$ of the particles in discharged drilling fluids and almost all of the cuttings settle rapidly. Within an hour of release, the settling plumes are diluted by a factor of 10,000 or more. Neff (1987) concludes that water-column organisms will never be exposed to drilling fluids long enough and at sufficiently high concentrations to show any acute or sublethal responses. Effects are limited to the sea floor in the immediate vicinity of and for a short distance downcurrent from the discharge. While those studies focused on WBMs, Brandsma and McKelvie (1994) conclude that the exposure concentration of drifting organisms to oil from discharged OBM cuttings particles appears to be several orders of magnitude below levels that would cause toxic effects in the water column.

In terms of toxicity, most WBMs, SBMs, and mineral-oil-type OBMs are non-toxic. Friedheim and Pantermuehl (1993) report that PAO-type SBMs easily meet the toxicity protocols established by the United States, Great Britain, Norway, and the Netherlands. Peresich et al. (1991) present data to demonstrate that ester-type SBMs easily meet toxicity standards.

Another potential for concern lies in exposure to metals through bioaccumulation in the food chain of the low concentrations of metals in drilling mud, principally cadmium and mercury. In drilling mud discharges, these metals are generally found in highly stable, insoluble forms. They have been shown to not bioaccumulate to harmful levels and are not 
biomagnified in the marine food webs (Neff 1988). More recent laboratory bioaccumulation tests found that fish exposed to SBM cuttings for 30 days had not taken up the SBM, while nearly all the tested fish exposed to OBM cuttings for 30 days showed accumulation of mineral oil in the guts, and about half of the tested fish showed accumulation in the tissues (Friedheim and Pantermuehl 1993).

Pore water quality is more likely to be influenced by sediment characteristics than by water column chemistry. Consequently, benthic sampling provides a better estimate of sea-floor biological health than does pore water modeling. This topic is covered in Section 4.2 .

\subsection{SEA-FLOOR IMPACTS}

Discharge of OBM cuttings poses a greater environmental impact on the sea floor than does discharge of WBM cuttings. OBM cuttings can significantly increase oil content in sediment and decrease biological abundance and diversity of immobile bottom-dwelling organisms in the affected area. Major biological impacts are limited to a zone of about 500 meters around the drilling platform and are primarily due to physical burial and anoxia caused by the heavy organic loading and the barrier that the OBM cuttings present to oxygen transport to the sediment (Davies et al. 1988). Within this 500-meter zone, recovery is slow compared with recovery in an area of WBM discharges. Beyond the 500-meter zone, a transition zone in which lesser biological effects are observed extends out to about 1,000 meters.

The EPA (1993b) reviewed 23 studies of the field impact of discharges of drilling fluids and drill cuttings (presumably WBMs). The review suggests that localized sea-floor impacts may occur, depending upon the type of mud discharged and the energy level of the sea-floor environment, but regional-scale impacts have not been identified. Other literature not surveyed by EPA also suggests that environmental impacts of WBMs and SBMs and their drill cuttings discharges are not extreme or long-lived. The extent and duration of impacts from discharge of muds and cuttings are effected by the degree of natural mixing and dispersion of the sediments.

Gillmor et al. (1985) conducted a benthic evaluation at a deep (120 meters), lowenergy site off the coast of New Jersey. Discharge of WBMs and cuttings caused a local decrease in the abundance of immobile, bottom-dwelling organisms because of physical burial and possibly inhibition of larval recruitment, but the discharges had little effect on diversity. Abundance levels of certain bottom-dwelling fish increased in the area of the drilling rig because of the additional bottom microrelief provided by the cuttings and the fallout of organic material from the community of organisms attached to the submerged portions of the platform (Gillmor et al. 1985; Neff 1987).

Neff et al. (1989) studied deep sites (80-140 meters) where WBMs and cuttings had been discharged in a high-energy environment at Georges Bank. In contrast to the results of Gillmor et al. (1985), Neff et al. (1989) observed only subtle changes in various benthic 
community parameters during and immediately after drilling. The degree of change observed was within the expected range of natural variation and appeared to have no effect on the benthic invertebrate and fish populations that support the rich commercial fishery of Georges Bank.

The amount of published data available on sea-floor impacts of SBMs is limited. Friedheim (1994b) reports that seabed studies in the Gulf of Mexico indicated that a PAOtype SBM was either degrading or dispersing significantly during a six-month period. Friedheim states that these results were in agreement with previous laboratory anaerobic testing of the PAO material and the indications from a simulated seabed study performed in Norway.

Gjøs et al. (1991) reported on two sea-floor surveys conducted at a well in the Norwegian sector of the North Sea, a portion of which was drilled with an ester-type SBM. The SBM cuttings were discharged on-site. The surveys collected chemical and biological samples at two perpendicular transects. The first survey was conducted two days after drilling and discharge of the cuttings had ceased, and the second survey was conducted at the same stations one year later.

Table 2 compares the two years for sediment ester concentration and the abundance and diversity of benthic organisms. The 1990 (initial) concentrations were elevated within 200 meters of the discharge point, but the 1991 concentrations were nearly all diminished except for one station at 100 meters from the discharge point. These results indicate that the ester had degraded relatively quickly in the environment.

In the benthic analysis, the 1990 data indicate that the effects were only observed out to 100 meters from the well. One year later, those stations had returned to normal levels of abundance and diversity. In this case, the effects of the SBM were limited both spatially and temporally. Within one year, benthic populations were back to normal (Gjøs et al. 1991).

Candler et al. (1995) examined sea-floor impacts at a well in the Gulf of Mexico, 4,650 feet of which was drilled with a PAO-type SBM. The cuttings were discharged on-site in 39 meters of water. Three sets of chemical samples were taken over a two-year period, and one set of benthic organism samples was collected. Two years after the SBM discharges were completed, three sites within 50 meters of the well exhibited an adversely affected benthic community and elevated levels of total petroleum hydrocarbons (TPH, an indicator for PAO). The remaining 13 sites had much lower TPH levels after the two-year period and had benthic populations that were comparable to four reference stations in terms of species abundance and diversity (Table 3 ).

Candler et al. (1995) concluded that discharges of cuttings from wells drilled with PAO-type SBMs have a greater impact on benthic communities within a 50-meter zone around the discharge point than do discharges of WBMs and cuttings. However, compared with North Sea discharges of cuttings from wells drilled with OBMs, the rate of recovery for SBM-contaminated areas was greatly improved. 
TABLE 2 Comparison of Two Sea-Floor Studies at a Well Drilled with an Ester-Type SBM

\begin{tabular}{|c|c|c|c|c|c|c|c|c|c|}
\hline \multirow[b]{2}{*}{ Station Number } & \multirow{2}{*}{$\begin{array}{l}\text { Location }^{\mathrm{a}} \\
(\mathrm{m})\end{array}$} & \multicolumn{2}{|c|}{$\begin{array}{c}\text { Mean } \\
\text { Sediment Ester } \\
\text { Concentration } \\
(\mathrm{mg} / \mathrm{kg}) \\
\end{array}$} & \multicolumn{2}{|c|}{$\begin{array}{r}\text { Number } \\
\text { of Taxa } \\
\end{array}$} & \multicolumn{2}{|c|}{$\begin{array}{l}\text { Number of } \\
\text { Individuals }\end{array}$} & \multicolumn{2}{|c|}{$\begin{array}{c}\text { Diversity } \\
\text { (Shannon- } \\
\text { Weiner } \\
\text { Index) } \\
\end{array}$} \\
\hline & & 1990 & 1991 & 1990 & 1991 & 1990 & 1991 & 1990 & 1991 \\
\hline 1 & $50 \mathrm{SW}$ & 85,300 & 0.21 & 4 & 51 & 16 & 379 & 1.5 & 4.3 \\
\hline 2 & $100 \mathrm{SW}$ & 46,400 & 0.22 & 7 & 44 & 167 & 370 & 0.96 & 4.24 \\
\hline 3 & $200 \mathrm{SW}$ & 208 & 1.34 & 52 & 38 & 290 & 212 & 4.52 & 4.31 \\
\hline 4 & $500 \mathrm{SW}$ & 0.98 & 0.43 & 50 & 43 & 308 & 625 & 4.53 & 2.61 \\
\hline 5 & $800 \mathrm{SW}$ & 0.42 & 0.18 & 57 & 49 & 284 & 365 & 4.72 & 4.36 \\
\hline 6 & $1,200 \mathrm{SW}$ & 0.38 & 0.31 & 56 & 53 & 308 & 322 & 4.54 & 4.71 \\
\hline 7 & $2,500 \mathrm{SW}$ & 0.26 & 0.39 & 51 & 45 & 316 & 230 & 4.64 & 4.54 \\
\hline 8 & $5,000 \mathrm{sW}$ & 0.30 & 0.36 & 56 & 52 & 336 & 334 & 4.50 & 4.49 \\
\hline 9 & $100 \mathrm{SE}$ & 360 & 11.68 & 35 & 52 & 234 & 408 & 3.39 & 4.41 \\
\hline 10 & $200 \mathrm{SE}$ & 97 & 0.34 & 52 & 57 & 290 & 395 & 4.66 & 4.37 \\
\hline 11 & $500 \mathrm{SE}$ & 2.44 & 5.28 & 51 & 52 & 255 & 367 & 4.75 & 3.98 \\
\hline 12 & $1,200 \mathrm{SE}$ & 0.25 & 0.18 & 47 & 41 & 224 & 259 & 4.58 & 4.28 \\
\hline Reference Site A & $-b$ & - & 0.25 & 56 & 48 & 385 & 340 & 4.59 & 4.18 \\
\hline Reference Site B & - & - & - & 53 & 58 & 368 & 329 & 4.33 & 4.73 \\
\hline
\end{tabular}

a Location is given in distance and direction from the discharge point.

b A "-" indicates no data available.

Source: Gjøs et al. (1991). 
TABLE 3 Benthic Conditions after Two Years at a Well Partially Drilled with a PAO-Type SBM

\begin{tabular}{|c|c|c|c|}
\hline Stations & $\begin{array}{l}\text { Number } \\
\text { of Taxa }\end{array}$ & $\begin{array}{l}\text { Number of } \\
\text { Individuals }\end{array}$ & $\begin{array}{l}\text { Diversity (Shannon- } \\
\text { Weiner Index) }\end{array}$ \\
\hline 3 Affected Stations ${ }^{a}$ & $8-22$ & $17-141$ & $1.69-2.25$ \\
\hline 13 Remaining Stations & $26-38$ & $162-280$ & $2.32-3.15$ \\
\hline 4 Reference Stations ${ }^{b}$ & $27-32$ & $152-219$ & $2.49-2.86$ \\
\hline
\end{tabular}

a 25 meters south, 25 meters west, and 50 meters south of well.

b 2,000 meters north, south, east, and west of well.

Source: Candler et al. (1995).

As stated earlier, SBMs are a diverse group of substances with widely different base fluids. The environmental impact from discharging SBM cuttings will vary depending on the base fluid and the energy of the environmental setting into which the cuttings are discharged. In general, SBMs have substantially lower environmental impacts than OBMs.

\subsection{NON-WATER-QUALITY ENVIRONMENTAL IMPACTS}

Non-water-quality impacts are additional environmental and safety impacts associated with use and disposal of different types of drilling mud. Such impacts include air pollution from transportation; energy use during transportation; disposal site factors (use of scarce disposal sites, potential site contamination, threats to groundwater); and worker safety from use, loading, and unloading of the material.

Each mud type causes or mitigates a range of indirect environmental impacts associated with its use and disposal. Indirect impacts appear to be most severe with OBMs and seem to be favorably mitigated by SBMs. The indirect impacts of WBMs are neutral; while most WBMs are discharged on-site, significant volumes of WBM waste are still disposed of off-site.

As noted earlier, major indirect impacts of off-site waste disposal result from use of OBMs and, to a far lesser extent, WBMs. Disposal of diesel-based OBMs may place toxic hydrocarbons and priority pollutants in landfills, where they have the potential to leach into groundwater or otherwise leak out of containment. Another significant indirect impact from such disposal is the air pollution generated by the transportation of large volumes of OBM wastes to shore. The EPA (1993a) estimates that 298 tons per year of additional air pollutants will be released as a result of implementing its final ELGs for the offshore oil and gas industry. The major sources of these emissions are the supply boats used to transport mud and cuttings to shore. Other equipment items with significant air emissions contributions include cranes, trucks, tractors, and bulldozers used in the onshore handling and disposal of the mud and cuttings. 
This level of air pollution is reduced by use of WBMs and the associated on-site disposal of WBM cuttings. Use of SBMs can also reduce indirect environmental impacts by virtue of shorter drilling times and the consequent reduced air emissions from drilling equipment. Indirect environmental impacts are further reduced for SBMs if on-site disposal of SBM cuttings is allowed.

Increased use of horizontal drilling techniques is another practice facilitated with SBMs or OBMs that has pollution prevention/reduction potential. Although data are not available to measure the full effect on drilling operations, SBMs or OBMs allow the drilling of extended-reach and horizontal wells, which reduce overall development costs.

Worker health and safety is another impact differing between mud types. A concern in this case is with diesel-based OBMs, which often contain hazardous substances and may cause irritation upon contact with the skin. Since oil field workers regularly come in contact with the mud they use, implementation of proper worker protection measures for diesel-based OBMs is necessary if this risk is to be minimized. Because of the potential hazards of diesel oil to workers, diesel-based OBMs are not frequently used offshore. WBMs occasionally may pose a similar problem for worker health and safety when a diesel oil pill or a toxic mud additive is used. SBMs can help minimize the worker health and safety risk caused by exposure since most synthetic base fluids exhibit low toxicity. Park et al. (1993) report that PAO-based SBMs have a much higher flash point than mineral oils, resulting in substantially fewer fumes being released. Friedheim (1994b) corroborates this with evidence that far fewer vapors are given off by PAOs compared with mineral oil and diesel oil and that PAO base fluid is not a skin or eye irritant. Peresich et al. (1991) provide similar evidence for an estertype SBM.

Avoidance of operational incidents, such as pipe stuck in the hole, also reduces pollution discharges. This widespread problem is often remedied in WBMs with use of an oil pill. An oil pill typically must be separately captured and disposed of in some manner other than overboard discharge. Some operators use a synthetic-based spotting fluid as a pill. This type of pill may meet EPA's discharge standards and avoid the need for separately capturing and disposing of the pill (Seraydarian 1988). The use of SBMs can aid in minimizing the incidence of stuck pipe in the first place, thus resulting in less downtime, reduced waste, and avoided pollution from this problem. 


\section{REGULATORY ISSUES}

\subsection{PREFERRED DISPOSAL TECHNIQUE}

Because discharge of drilling mud to surface waters is covered under Section 402 of the Clean Water Act, drilling operators must apply for EPA and/or state permits for such discharges. This requirement applies to all offshore operators in the oil and gas industry. Mud disposal is less of a problem for onshore operators, who usually dispose of mud by on-site burial (which is not covered under the Clean Water Act), off-site treatment and disposal, or injection.

Offshore operators have a more serious and potentially more costly problem than do onshore operators. An approved onshore disposal site might be hundreds of miles from an offshore rig by barge and truck. Offshore storage of large volumes of mud and drill cuttings until hauling and disposal creates a major cost and logistical problem. The preferred disposal method for used WBMs and drill cuttings is direct discharge into surrounding seawater. OBMs and their drill cuttings cannot be discharged offshore; these muds are recycled, and the cuttings are hauled to shore. The expensive SBMs are recycled, and the drill cuttings are discharged offshore whenever possible. The ability to discharge SBM cuttings on-site is the key element in making SBMs economically feasible in many applications.

\subsection{EPA REGULATORY APPROACH}

In its final offshore ELGs issued on March 4, 1993, EPA determined that it is not technically feasible to control each toxic constituent of drilling muds and cuttings directly. EPA opted for using a toxicity test requirement and placing limits on drilling mud contaminants that serve as indicators for toxic substances - free oil and diesel oil are indicators of toxic organic compounds, and cadmium and mercury (in stock barite) are indicators of toxic metals.

Toxicity is a measurement used to determine if pollutant concentrations are at levels that can cause lethal effects to organisms exposed to various concentrations of drilling mud. EPA's technology basis for this control is product substitution of less toxic additives or, if the toxicity limit cannot be met, transport of drilling mud to shore for disposal. In its final offshore ELGs, EPA requires operators to conduct a toxicity bioassay on discharged drilling muds. A mud that passes the bioassay must have an LC50 greater than $30,000 \mathrm{ppm}$. The $30,000 \mathrm{ppm}$ toxicity limitation is based on EPA's findings on toxicity data received from round-robin testing of eight generic mud types sometimes used by the industry.

The EPA has also determined that substitutes are available for most significantly toxic mud additives (EPA 1992, 1993c). In its justification for the 30,000-ppm toxicity standard, EPA believes that the limit is technologically achievable because industry has operated under NPDES permits imposing such a limit since 1987 . These permits were issued 
by EPA regional offices and established toxicity limits based on "best professional judgment" (BPJ).

\subsection{LIMTTATIONS OF EPA APPROACH}

Technological developments in the drilling industry appear to have outgrown the ELGs' regulatory categories. The ELGs do not recognize the use of pollution prevention systems such as SBMs as a control technology for conventional pollutants (Burke 1994). Neither do the ELGs consider the engineering aspects of the effectiveness of a drilling mud as a technology that could be used to reduce overall pollution levels.

The limitations of EPA's regulatory approach may result partially from past conventional wisdom that focused on two categories of mud, OBMs and WBMs. During the extended rule-making process, EPA focused on current technologies in use, their environmental impacts, and the effects of proposed regulations. The current availability of SBMs as a technical alternative to past and present practices may warrant regulatory consideration. Operators are concerned that some types of SBMs may not pass EPA's static sheen test for demonstrating that no free oil is present, and, therefore, the SBM cuttings would be prohibited from on-site discharge. If on-site discharge of SBM cuttings is not allowed, SBMs often are no longer economically attractive. Reevaluation of the current policy should include consideration of the limitations in the approach and clarification or amendment of the ELGs so that the use of SBMs is not unnecessarily precluded. The following are among the specific measures that need additional clarification:

- The term "synthetic base fluid" should be clearly and simply defined to include low-toxicity SBM products being developed.

- Application of the static sheen test should be evaluated. The test is intended to detect free crude oil, diesel oil, or mineral oil in drilling mud discharges. However, the continuous phase of some SBMs is lighter than water and could cause a detectable film in the static sheen test apparatus. While this film does not result from the type of free oil that EPA intended as an indicator of priority pollutants, it might be interpreted as a failure of the sheen test and thus preclude on-site discharge of the associated drill cuttings. The static sheen test procedure or interpretation of results should be clarified or amended to ensure that the original intent is accomplished, but that a wide range of pollution-preventing SBMs is not inadvertently subjected to unnecessary barriers.

Implicit in this revised approach is the recognition that EPA regulations must be flexible and responsive to the development of new technologies that reduce environmental impacts. Balancing environmental protection requirements with the need to encourage the development and use of new techniques and pollution prevention technologies should be an objective of a new approach to limitations on discharges. 


\section{CONCLUSIONS AND RECOMMENDATIONS}

Although they are focused on limiting end-of-pipe discharges from offshore platforms, EPA's ELGs have had desirable side effects with major ramifications for offshore operators. One prominent effect has been the development of innovative alternative SBM systems that can provide major benefits in terms of pollution prevention, operating costs, drilling efficiency, and performance.

SBMs were developed to provide drilling fluids with performance properties similar to those of OBMs, but whose cuttings could be approved for discharge. Widespread application of this new technology in the United States is constrained by regulatory uncertainty over specific definitions and requirements in the ELGs and the resultant NPDES permits intended to curtail discharges of OBMs containing toxic pollutants into the marine environment. EPA regulations were not drafted with full consideration of the recent development of innovative mud technologies, including SBMs. EPA should consider revising or clarifying regulations to specifically address appropriate standards for SBMs.

The EPA's offshore ELGs use a command-and-control, end-of-pipe approach that runs directly counter to the source reduction/pollution prevention approach that EPA has made an emerging policy priority. Greater regulatory flexibility in encouraging innovation and new technology development can ease the introduction of alternative pollution prevention technology.

The current regulatory wording of controls on offshore discharges suggests, however, that EPA may not be able to exercise the flexibility needed to resolve the present regulatory situation limiting the use of SBMs. To accomplish this goal, EPA should consider either (1) clarifying the present ELGs so that non-toxic and environmentally acceptable SBMs can comply or (2) establishing a new mud category for SBMs with appropriate controls for that category. Either of these approaches would involve substantial changes to EPA's past policies.

This report has identified several areas of research that could assist in sound policy development but that need additional data generation and verification. These research topics include the following:

- An expansive comparative assessment of the sea-floor impacts of SBMs compared with those of the two other types of mud, and

- A comparative environmental impact assessment of SBMs, WBMs, and OBMs once the primary data gaps have been filled. 


\section{REFERENCES}

Ayers, R.C., Jr., 1994, Personal communication from Ayers (Robert Ayers \& Associates, Houston, Texas) to C. Burke (Argonne National Laboratory, Washington, D.C.), June 26.

Ayers, R.C., Jr., et al., 1985, "The Generic Mud Concept for NPDES Permitting of Offshore Drilling Discharges," Journal of Petroleum Technology, p. 475, March.

Brandsma, M.G., and S. McKelvie, 1994, "Modeling North Sea Oil Based Mud Cuttings Discharges to Assess Environmental Loading: An E\&P Forum Study," Proc. of Offshore Technology Conference, Houston, Texas, May.

Burke, C.J., 1994, "Regulating Toxicity in Drilling Mud: An Innovative Approach Using Pollution Prevention," in Environmental Issues and Solutions in Petroleum Exploration, Production and Refining, PennWell Books, Tulsa, Okla.

Candler, J.E., et al., 1995, "Seafloor Monitoring for Synthetic-Based Mud Discharged in the Western Gulf of Mexico," presented at Society of Professional Engineers, Houston, Texas, March.

Candler, J.E., et al., 1993, "Synthetic-Based Mud Systems Offer Environmental Benefits over Traditional Mud Systems," presented at Society of Petroleum Engineers, San Antonio, Texas, March.

Carlson, T., 1994, Memorandum from Carlson (Baroid Drilling Fluids, Inc., Houston, Texas) to C. Burke (Argonne National Laboratory, Washington, D.C.), May 31.

Christiansen, C., 1991, "From Oil-Based Mud to Water-Based Mud," Proc. First International Conference on Health, Safety, and the Environment, Society of Petroleum Engineers, Nov.

Davies, J.M., et al., 1988, "Environmental Effect of Oil Based Mud Drilling in the North Sea," Proc. of the 1988 International Conference on Drilling Wastes, Calgary, Canada, April.

EPA - see U.S. Environmental Protection Agency.

Friedheim, J.E., 1994a, "Drilling with Synthetic Fluids in the North Sea - An Overview," presented at the IBC Conference on Drilling Technology, Aberdeen, Scotland, Nov.

Friedheim, J.E., 1994b, "The ABCs about PAOs," presented at the IBC Conference on the Prevention of Oil Discharge from Drilling Operations - The Options, Aberdeen, Scotland, June.

Friedheim, J.E., and R.M. Pantermuehl, 1993, "Superior Performance with Minimal Environmental Impact: A Novel Nonaqueous Drilling Fluid," presented at Drilling Conference sponsored by Society of Petroleum Engineers/International Association of Drilling Contractors, Amsterdam, The Netherlands, Feb. 
Gillmor, R.B., et al., 1985, "Effects of Exploratory Drilling Discharges on the Benthos," Wastes in the Ocean, Vol. 4, John Wiley \& Sons, New York, New York.

Gjøs, N., et al., 1991, ULA Well Site 7/12-9 Environmental Survey 1991, prepared by Field Studies Council Research Center for Senter for Industriforskning, Oslo, Norway, Dec.

McMordie, W.C., 1980, "Oil Base Drilling Fluids," in Proc. of Symposium on Research of Environmental Fate and Effects of Drilling Fluids and Cuttings, Lake Buena Vista, Fla., Jan.

National Research Council, 1983, Drilling Discharges in the Marine Environment, National Academy Press, Washington, D.C.

Neff, J.M., 1987, "Biological Effects of Drilling Fluids, Drill Cuttings and Produced Water," in Long-Term Environmental Effects of Offshore Oil and Gas Development, D.F. Boesch and N.N. Rabalais (editors), Elsevier Applied Science, London, United Kingdom.

Neff, J.M., 1988, Bioaccumulation and Biomagnification of Chemicals from Oil Well Drilling and Production Wastes in Marine Food Webs: A Review, prepared by Battelle Ocean Sciences for American Petroleum Institute, Washington, D.C.

Neff, J.M., et al., 1989, "Impacts of Exploratory Drilling for Oil and Gas on the Benthic Environment of Georges Bank," Marine Environment Research 27:77-114.

Offshore Operators Committee, 1987, "Gulf of Mexico Spotting Fluid Survey," prepared by R.C. Ayers, Jr., and J.E. O'Reilly, Exxon Production Research Company, Houston, Texas, and L.R. Henry, Chevron, USA, Inc., Houston, Texas, April 4.

OOC - see Offshore Operators Committee.

Park, S., et al., 1993, "The Success of Synthetic-Based Drilling Fluids Offshore Gulf of Mexico," presented at Society of Petroleum Engineers, Richardson, Texas.

Peresich, R.L., et al., 1991, "Development and Field Trial of a Biodegradable Invert Emulsion Drilling Fluid," presented at Drilling Conference sponsored by Society of Petroleum Engineers/International Association of Drilling Contractors, Amsterdam, The Netherlands, March.

Seraydarian, H., 1988, Letter from Seraydarian (U.S. Environmental Protection Agency, Region IX, San Francisco, Calif.) authorizing the use and discharge of certain synthetic-based spotting fluids under general permit CA0110516, Dec. 12.

U.S. Environmental Protection Agency, 1992, "Fact Sheet for NPDES Permit No. CA0110842 and CA0110851," EPA Region IX, San Francisco, Calif., May.

U.S. Environmental Protection Agency, 1993a, Development Document for Effluent Limitation Guidelines and Standards for the Offshore Subcategory of the Oil and Gas Extraction Point Source Category, EPA 821-R-93-003, Washington, D.C., Jan. 
U.S. Environmental Protection Agency, 1993b, Regulatory Impact Analysis of Final Effluent Limitations Guidelines and Standards for the Offshore Oil and Gas Industry, EPA 821-R-93002, Washington, D.C., Jan.

U.S. Environmental Protection Agency, 1993c, "Fact Sheet for NPDES Permit No. AK005205-1," EPA Region X, Seattle, Wash., April.

White, W., 1994a, Unpublished data, Marathon Oil, Lafayette, La., May 26.

White, W., 1994b, Unpublished data, Marathon Oil, Lafayette, La., June 16. 